\title{
Optimization of Three-Step Method For Biodiesel Production From Waste Cook Oil
}

\author{
Kaniz Ferdous $^{1 *}$, M. Rakib Uddin ${ }^{1}$, M. Rahim Uddin ${ }^{1}$, Maksudur R. Khan ${ }^{1,2,}$, M. A. Islam ${ }^{1}$ \\ ${ }^{1}$ Department of Chemical Engineering and Polymer Science, Shahjalal University of Science and \\ Technology (SUST), Sylhet 3114, Bangladesh. \\ ${ }^{2}$ Faculty of Chemical and Natural Resources Engineering, Universiti Malaysia Pahang, \\ 26300 Gambang, Kuantan, Pahang, Malaysia.
}

\begin{abstract}
In this paper, production of biodiesel from Waste Cook Oil (WCO) by three-step method and optimization of the process were studied. The properties of raw oil were measured by standard methods. The raw oil containing $1.9 \mathrm{wt} \%$ Free Fatty Acid (FFA) and viscosity was $54.53 \mathrm{~mm}^{2} / \mathrm{s}$. Biodiesel was prepared from WCO by three-step method. In the three-step method, the first step was saponification of the oil followed by acidification to produce FFA and finally esterification of FFA to produce biodiesel. The reaction parameters in saponification, acidification and esterification reaction were optimized. Silica gel was used during esterification reaction to adsorb water produced in the reaction and silica gel to FFA ratio was 1.5:10 wt/wt. Hence the reaction rate was increased and finally the FFA was reduced to 0.98 wt $\%$. A factorial design was studied for esterification reaction to obtain the higher yield of biodiesel. Finally various properties of biodiesel such as FFA, viscosity, specific gravity, cetane index, pour point, flash point etc. were measured and compared with biodiesel and petro-diesel standard.
\end{abstract}

\section{INTRODUCTION}

Diesel oil, generated from petroleum by refining, is an important fuel for many engines. Combustion of diesel produces carbon dioxide, which is assumed to contribute to the global warming. Furthermore, mineral fuels contain sulfur, which, if not removed prior to combustion, is a cause of acid rain. The discussion on reduction of $\mathrm{CO}_{2}$ emissions and on high prices for fossil diesel fuel leads to an enforced search for production of fuels from renewable sources. In the announcements of the EU-committee, the intention to replace $5.8 \%$ fossil diesel fuel with fuel from biogeneous sources [1].

Biodiesel, a mixture of fatty acid methyl esters (FAME), is a clean-burning fuel derived from vegetable oils or animal fat and is an advantageous alternative to fossil diesel fuel because of its biodegradability, biorenewable nature, very low sulfur content and toxicity, low volatility or flammability, good transport and storage properties, higher cetane number, and its salutary atmospheric $\mathrm{CO}_{2}$ balance for production [2]. In Bangladesh the potentiality of producing oil source was investigated and it was found that the production potential was not too high. As we have a very large population, the edible oil sources cannot be employed for the biodiesel production. Moreover we have extreme limitation of land. So additional land acquiring is also impossible for the production of oil seeds. The oil seed source that can be used for biodiesel production in Bangladesh are WCO, mustard oil, sesame oil, coconut oil, peanut oil, linseed oil, castor oil, nahor oil etc. [3].

The high cost of biodiesel is mainly due to the cost of virgin vegetable oil. Therefore, it is not surprising that the biodiesel produced from vegetable oil (for example, pure soybean oil) costs much more than petroleum based diesel. Therefore, it is necessary to explore ways to reduce production costs of biodiesel. In this sense, methods that permit minimizing the costs of the raw material are of special interest. The use of waste frying oil, instead of virgin oil, to produce biodiesel is an effective way to reduce the raw material cost because waste frying oil is estimated to be about half the price of virgin oil [4].

There are different methods for biodiesel preparation like base or acid catalyzed transesterification [5,6], two step method [7] and three-step method [8]. Encinar et. al., (2005) [9] prepared biodiesel from WCO by base catalyzed transesterification but the reaction yield was too low than two-step method was conducted to increase the reaction yield, Zheng et. al., (2006) [4] produced biodiesel from WCO by acid catalyzed transesterification but the molar ratio of oil to methanol was 1:74. In this method huge amount methanol required for reaction and additional cost involved for the separation of biodiesel. In the present study biodiesel was prepared from WCO by three-step method to increase the reaction yield and minimize the methanol molar ratio. Additionally optimization study was done by the application of factorial design to find out the better reaction conditions.

\section{MATERIALS AND METHODS}

\subsection{Chemicals}

Methanol (99-100\%), ethanol (99-100\%), calcium oxide $(\mathrm{CaO})$, sodium hydroxide pellets $(96 \%)$, potassium hydroxide pellets (>84\%), phenolphthalein ( $\mathrm{pH} 8.2-9.8)$, 
acetone (99\%), diethyl ether, hydrochloric acid (37\%), sulfuric acid (98\%), iodine, sodium iodide, bromine, carbon tetrachloride, glacial acetic acid, potassium dichromate etc. All the chemicals were used as analytical reagent grade.

\subsection{Raw materials}

WCO (palm oil and soybean oil) was collected from local restaurants located in Sylhet city in Bangladesh. The oil was filtered and its properties were measured.

\subsection{Biodiesel preparation by Three- step method}

For saponification process required amount of WCO was taken in a three necked flask and mixed with different stoichiometric amount of aqueous calcium oxide solution [8]. The mixture was heated under reflux with vigorous stirring at temperature of $100{ }^{0} \mathrm{C}$ for different time. After saponification, produced calcium soap solution was treated with different stoichiometric amount of concentrated hydrochloric acid at a temperature of $65-70{ }^{\circ} \mathrm{C}$. After dissolving the soap, the fatty acid contents were separated in separatory funnel. Hot water wash was given for removing mineral acid from the fatty acid. The FFA content was determined by titration method. When acidification was completed, produced FFA was reacted with different stoichiometric amount of methanol under reflux with vigorous stirring at different temperature, catalyst concentration, different molar ratio of methanol to FFA and different time. All the reaction parameters were optimized. Silica gel was used during esterification reaction to adsorb water produced in esterification reaction. After preparing the biodiesel from WCO various physico-chemical properties were measured and compared with the biodiesel and petro-diesel standard.

\subsection{Analytical methods for oil and biodiesel}

To determine FFA of sample and biodiesel, $1 \mathrm{~mL}$ of oil and biodiesel were weighed in $\mathrm{gm}$, then dispersed in $5 \mathrm{~mL}$ diethyl-ether solution followed by titration against $0.1 \mathrm{M} \mathrm{KOH} \mathrm{[10].} \mathrm{Saponification} \mathrm{value} \mathrm{(SV)} \mathrm{was}$ determined by method described by Jeffery et al., (1991) [10].To determined S.V. 2 gm sample was taken in $50 \mathrm{~mL}$ alcoholic $\mathrm{KOH}$ then heated at $65{ }^{\circ} \mathrm{C}$ with vigorous stirring for $30 \mathrm{~min}$ and titrated against $0.5 \mathrm{M}$ hydrochloric acid. The iodine value (IV) were determined by titrating $0.01 \mathrm{~N}$ sodium thiosulfate to the mixture of tested fuel and chemical reagents until the disappearance of the blue color based on the analysis methods of American Oil Chemist's Society [11]. IV was calculated by

the following equation (1).

$\mathrm{IV}=(B-S) \times N \times 0.001269 / \mathrm{W}$

where, $S$ and $B$ are the amounts (in unit of $\mathrm{mL}$ ) of sodium thiosulfate titrated for the tested sample and blank sample respectively; $N$ is the molar concentration (in unit of mol/L) of sodium thiosulfate and $W$ is the weight (in unit of gm) of the tested sample.

Physical properties color, moisture content and density of the sample were by the following ASTM D 1500, ASTM D 1744 (Karl fisher method), ASTM D 1480/81 and ASTM D 240. Viscosity, cloud point, pour point were determined by standards ASTM D445 respectively.

\section{RESULTS AND DISCUSSION}

\subsection{Characterization of WCO}

The properties of WCO such as viscosity, specific gravity, moisture content, saponification value, pour point, cloud point etc were measured and presented in Table 1.

Table 1. Properties of WCO

\begin{tabular}{|l|c|}
\hline \multicolumn{1}{|c|}{ Properties } & Experimental value \\
\hline Physical state & Liquid \\
\hline Color & Deep oily \\
\hline Specific gravity at $25^{\circ} \mathrm{C}$ & 0.90 \\
\hline $\begin{array}{l}\text { Kinematic viscosity, } \mathrm{mm}^{2} / \mathrm{s} \text { at } \\
40^{\circ} \mathrm{C}\end{array}$ & 54.53 \\
\hline FFA content $(\mathrm{wt} \%$ of oil) & 1.9 \\
\hline $\begin{array}{l}\text { Average molecular weight of } \\
\text { FFA (gm/mol) }\end{array}$ & 275.5 \\
\hline $\begin{array}{l}\text { Molecular weight of oil } \\
\text { (gm/mol) }\end{array}$ & 864.5 \\
\hline $\begin{array}{l}\text { Saponification value }(\mathrm{mg} \text { of } \\
\text { KOH/gm of oil) }\end{array}$ & 238 \\
\hline Cloud point $\left({ }^{\circ} \mathrm{C}\right)$ & 12 \\
\hline Pour point $\left({ }^{\circ} \mathrm{C}\right)$ & 6 \\
\hline
\end{tabular}

\subsection{Biodiesel prepared by three-step method}

3.2.1 FFA preparation: FFA was prepared from WCO by saponification followed by acidification. Saponification was done by the method described above. Saponification was done with different stoichiometric amount of $\mathrm{CaO}$. After saponification and acidification FFA was produced.

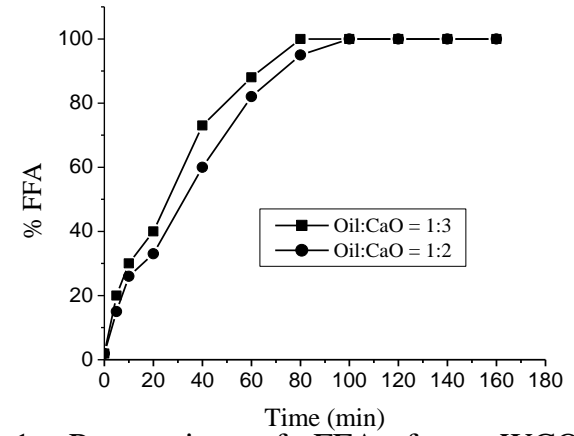

Fig. 1: Preparation of FFA from WCO through saponification and acidification in aqueous solution 
[Reaction temperature $=100{ }^{0} \mathrm{C}$ under reflux with vigorous stirring].

The results are present in Fig. 1. From the Fig. 1 it can be seen that, the optimum molar ratio of oil to $\mathrm{CaO}$ was 1:2 and reaction time was $120 \mathrm{~min}$.

3.2.2 Biodiesel Preparation from FFA: The methanol to FFA molar ratio, catalyst concentration, temperature and silica gel dosages are the important parameters that affecting the FFA conversion to biodiesel. The effect of methanol to FFA molar ratio, catalyst concentration, temperature and amount of silica gel on conversion of FFA was investigated. The results are shown in Fig. 2,3,4,5.From the Fig. 2,3,4, it was found that the FFA conversion to biodiesel was $98 \%$ at $6: 1$ molar ratio of methanol to FFA, $5 \mathrm{wt} \%$ catalyst $(\mathrm{HCl})$ concentration, $60{ }^{\circ} \mathrm{C}$ temperature. From the Fig. 5, it can be seen that $98 \%$ conversion was achieved within 80 minutes in presence of silica gel and reaction rate was increased.

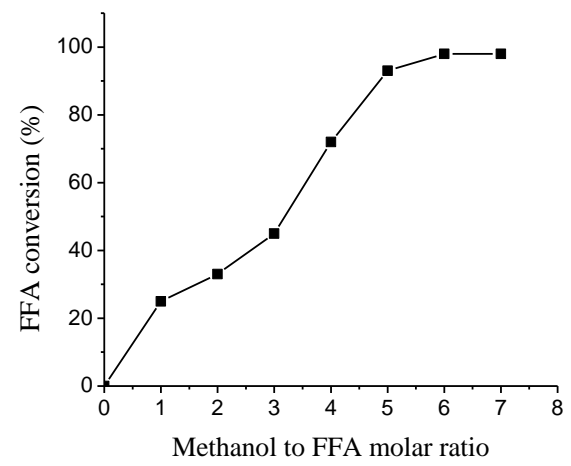

Fig. 2: Effect of Methanol to FFA molar ratio on FFA conversion [temperature $60{ }^{\circ} \mathrm{C}$, catalyst $(\mathrm{HCl}) 5 \mathrm{wt} \%$ of FFA, time 120 min under reflux with vigorous stirring].

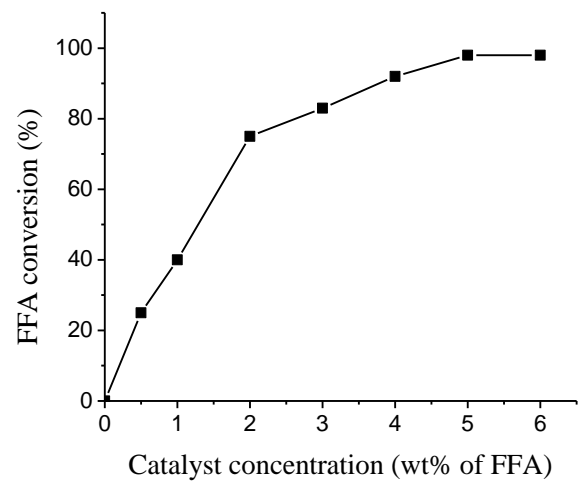

Fig. 3: Effect of catalyst $(\mathrm{HCl})$ concentration on esterification reaction [Reaction temperature $60{ }^{\circ} \mathrm{C}$, methanol to FFA ratio $6: 1$, Reaction time $120 \mathrm{~min}$, under reflux with vigorous stirring].

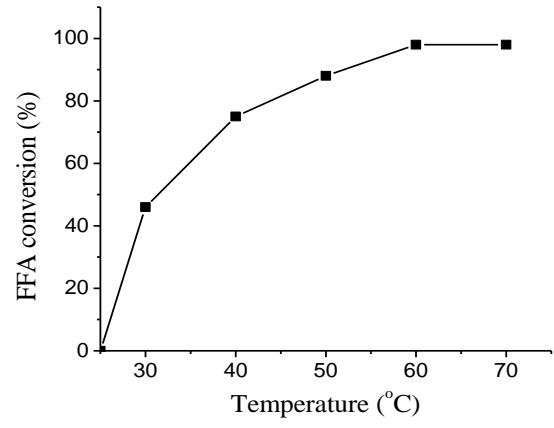

Fig. 4: Effect of Temperature on esterification reaction [Catalyst $(\mathrm{HCl})$ concentration $5 \mathrm{wt} \%$ of FFA, methanol to FFA molar ratio 6:1, Reaction time $120 \mathrm{~min}$, under reflux with vigorous stirring].

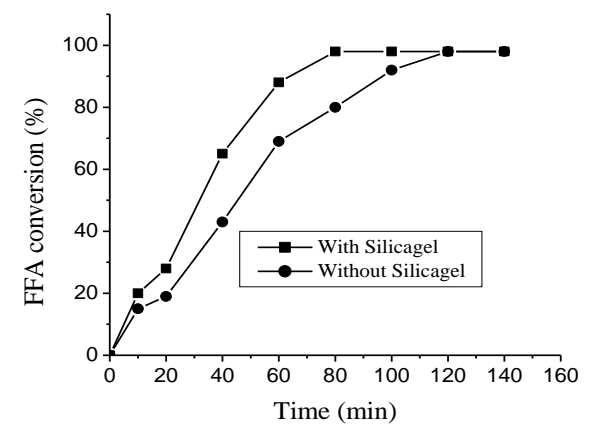

Fig. 5: Conversion of FFA to biodiesel at different methanol to FFA molar ratio in absence and presence of silica gel [Reaction temp. $60{ }^{\circ} \mathrm{C}$ and Catalyst $(\mathrm{HCl})$ concentration $5.0 \%$ wt of FFA under reflux with vigorous stirring].

\subsection{Optimization study}

Four factors (methanol to FFA molar ratio, catalyst concentration, temperature and reaction time) affect the biodiesel production process from WCO. To study the optimization of process, a factorial design was carried out. The experiments were carried out according to halfReplicate of $2^{4}$ full factorial design. Table 2 shows the decoding values for methanol to FFA molar ratio, catalyst concentration, reaction temperature and reaction time. Eight set of experiments were run for the factorial design and the results are shown in Table 3. Table 4 presents the values of sample variances.

Table 2. Decoding values of independent variables used in the experimental design

\begin{tabular}{|c|c|c|}
\hline Factors & Max. $(+1)$ & Min. $(-1)$ \\
\hline Molar ratio $\left(\mathrm{X}_{1}\right)$ & 8 & 3 \\
\hline Catalyst conc. $\left(\mathrm{X}_{2}\right)$ & 6 & 2 \\
\hline Temperature, ${ }^{\circ} \mathrm{C}\left(\mathrm{X}_{3}\right)$ & 60 & 40 \\
\hline Time $(\mathrm{min})\left(\mathrm{X}_{4}\right)$ & 90 & 30 \\
\hline
\end{tabular}


Table 3. Design of the experiment using coded value

\begin{tabular}{|c|c|c|c|c|c|c|c|c|c|c|c|c|}
\hline $\begin{array}{c}\text { No. of } \\
\text { runs }\end{array}$ & $\mathrm{X}_{\mathrm{o}}$ & $\mathrm{X}_{1}$ & $\mathrm{X}_{2}$ & $\mathrm{X}_{3}$ & $\mathrm{X}_{4}$ & $\mathrm{Y}_{1}$ & $\mathrm{Y}_{2}$ & $\mathrm{Y}_{3}$ & $\mathrm{Y}_{4}$ & $\mathrm{Y}_{5}$ & $\bar{Y}$ & $\mathrm{~S}_{\mathrm{i}}{ }^{2}$ \\
\hline 1 & +1 & +1 & +1 & +1 & +1 & 98.3 & 98.98 & 97.49 & 97.03 & 99.04 & 98.17 & 0.80 \\
\hline 2 & +1 & +1 & +1 & -1 & -1 & 75.28 & 77.99 & 74.62 & 77.87 & 77.67 & 76.69 & 2.58 \\
\hline 3 & +1 & +1 & -1 & +1 & -1 & 94.13 & 93.12 & 96.09 & 93.07 & 95.06 & 94.30 & 1.68 \\
\hline 4 & +1 & +1 & -1 & -1 & +1 & 93.84 & 91.76 & 94.02 & 91.65 & 90.52 & 92.36 & 2.30 \\
\hline 5 & +1 & -1 & +1 & +1 & -1 & 90.62 & 91.94 & 91.51 & 92.84 & 90.12 & 91.40 & 1.16 \\
\hline 6 & +1 & -1 & +1 & -1 & +1 & 74.15 & 72.07 & 73.99 & 73.96 & 71.78 & 73.20 & 1.35 \\
\hline 7 & +1 & -1 & -1 & +1 & +1 & 86.73 & 84.10 & 84.23 & 87.32 & 85.57 & 85.60 & 2.10 \\
\hline 8 & +1 & -1 & -1 & -1 & -1 & 75.62 & 76.13 & 76.50 & 75.97 & 78.37 & 76.52 & 1.16 \\
\hline & & & & & & & & & & & $\sum \bar{Y}=$ & $\sum \mathrm{S}_{\mathrm{i}}{ }^{2}=$ \\
& & & & & & & & & & & 688.24 & 13.13 \\
\hline
\end{tabular}

Table 4. Sample Variances

\begin{tabular}{|l|l|l|l|}
\hline $\mathrm{S}_{1}{ }^{2}$ & 0.80 & $\mathrm{~S}_{5}{ }^{2}$ & 1.16 \\
\hline $\mathrm{S}_{2}{ }^{2}$ & 2.58 & $\mathrm{~S}_{6}{ }^{2}$ & 1.35 \\
\hline $\mathrm{S}_{3}{ }^{2}$ & 1.68 & $\mathrm{~S}_{7}{ }^{2}$ & 2.10 \\
\hline $\mathrm{S}_{4}{ }^{2}$ & 2.30 & $\mathrm{~S}_{8}{ }^{2}$ & 1.16 \\
\hline
\end{tabular}

Where $\mathrm{Y}$ is the conversion of FFA to biodiesel in esterification reaction and $\bar{Y}$ is average value of Y. The sample variances were determined and tested for homogeneity on the basis of Cochran's criterion. It was found that the sample variances are homogeneous for the significance level $\alpha=0.05$ and the number of degrees of freedom $v_{1}=4$ and $v_{2}=8$ and the error mean square was 1.65.The complete regression equation describes the contributions of the various factors on the outcome (response) of the biodiesel conversion.

$\widehat{Y}=b_{0}+b_{1} X_{1}+b_{2} X_{2}+b_{a} X_{a}+b_{4} X_{4}+b_{12} X_{12}+(2)$ $b_{1 a} X_{1 a}+b_{2 a} X_{2 a}$

The coefficients of the regression equation were estimated and the significance of the coefficients was tested using the student T-test. Only one coefficient appeared as insignificant for the significance level $\alpha=$ 0.01 . Neglecting the insignificant coefficient the final regression equation becomes as:

$\left.\widehat{\mathrm{Y}}=86.03+4.34 \mathrm{X}_{1}-1.16 \mathrm{X}_{2}+6.53 \mathrm{X}_{\mathrm{a}}+1.29 \mathrm{X}_{4}+3\right)$ $1.78 \mathrm{X}_{12}+3.58 \mathrm{X}_{23}$

Using the Fisher's test the adequacy fitness of the regression equation was determined. With $\alpha=0.01, v_{1}$ $=1$ and $v_{2}=32$ the tabulated value of Fisher's $F$ was 7.5 where as our experimental value was 5.66. Therefore the equation fits in the experiment.

\subsection{Properties of biodiesel}

The properties of produced biodiesel such as viscosity, FFA content, moisture content, pour point, cloud point, saponification value, iodine value, specific gravity were presented in Table 5 and compared with standard biodiesel and petro-diesel values. The reaction yield was $78 \%$.

Table 5. Properties of biodiesel produced from WCO by three-step method and comparison with standard biodiesel and petro-diesel values.

\begin{tabular}{|c|c|c|c|}
\hline Properties & $\begin{array}{l}\text { Produced } \\
\text { biodiesel } \\
\text { value }\end{array}$ & $\begin{array}{c}\text { Biodiesel } \\
\text { Standard } \\
{[8.12]}\end{array}$ & $\begin{array}{c}\text { Petro- } \\
\text { Diesel } \\
\text { standard } \\
{[12]}\end{array}$ \\
\hline $\begin{array}{c}\text { Specific gravity, } \\
\text { at } 25^{\circ} \mathrm{C}\end{array}$ & 0.811 & $\begin{array}{l}0.88(\text { at } \\
\left.15.5^{0} \mathrm{C}\right)\end{array}$ & $\begin{array}{c}0.85(\text { at } \\
\left.15.5^{0} \mathrm{C}\right)\end{array}$ \\
\hline $\begin{array}{c}\text { Kinematic } \\
\text { viscosity } \\
\left(\mathrm{mm}^{2} / \mathrm{s}\right) \text {, at } 40^{\circ} \mathrm{C}\end{array}$ & 3.93 & $1.9-6.0$ & $1.3-4.1$ \\
\hline $\begin{array}{l}\text { FFA content } \\
(\mathrm{wt} \%)\end{array}$ & 0.98 & - & - \\
\hline $\begin{array}{l}\text { Moisture content } \\
(\text { vol } \%)\end{array}$ & 0.10 & $\begin{array}{l}0.05 \% \\
\max .\end{array}$ & 0.161 \\
\hline $\begin{array}{l}\text { Saponification } \\
\text { value (mg } \\
\mathrm{KOH} / \mathrm{gm} \text { oil) }\end{array}$ & 187 & - & - \\
\hline Flash point $\left({ }^{0} \mathrm{C}\right)$ & 150 & $\begin{array}{c}100 \text { to } \\
170\end{array}$ & 60 to 80 \\
\hline Iodine value & 84 & - & - \\
\hline Cloud point $\left({ }^{\circ} \mathrm{C}\right)$ & 2 & -3 to 12 & -15 to 5 \\
\hline Pour point $\left({ }^{\circ} \mathrm{C}\right)$ & 0 & -15 to 10 & $\begin{array}{l}-35 \text { to }- \\
15 \\
\end{array}$ \\
\hline
\end{tabular}




\section{CONCLUSION}

Biodiesel was prepared from WCO by three-step method, in three-step method aqueous calcium oxide solution was used for saponification, the molar ratio of oil to $\mathrm{CaO}$ and reaction time were optimized. The optimum molar ratio for saponification by aqueous calcium oxide was $1: 2$ oil to $\mathrm{CaO}$ and reaction time was $120 \mathrm{~min}$ at $100{ }^{\circ} \mathrm{C}$. In acidification the molar ratio of soap to hydrochloric acid was 1:2 for calcium soap. In Esterification the optimum molar ratio of methanol to FFA was $6: 1$, the catalyst $(\mathrm{HCl})$ concentration was 5 wt $\%$ of FFA, the reaction temperature was $60{ }^{\circ} \mathrm{C}$ and the reaction time was $120 \mathrm{~min}$, with silica gel reaction time was reduced to $80 \mathrm{~min}$ and FFA content was reduced to $0.98 \%$. A factorial design was applied to find the optimum conditions for esterification reaction. At optimum conditions $98 \%$ conversion of the FFA to FAME was obtained. The properties of produced biodiesel such as viscosity, specific gravity, cloud point, pour point, flash point are nearest to the petro-diesel. The present experimental results support that produced biodiesel from WCO by this method can be successfully used as diesel.

\section{REFERENCES}

[1]. Chinta Reddy, Venkat Reddy, Reed Oshel, and John G. Verkade, Energy \& Fuels, 20 (2006) 1310.

[2]. Cerce Tanja, Peter Siegfried, and Eckhard Weidner, Ind. Eng. Chem. Res., 40 (2005) 9535.

[3]. http://www.eoearth.org/article[Accessed 5 April 2010].

[4]. S. Zheng, M. Kates, M.A. Dube, and D.D. McLean, Biomass \& Bioenergy, 30(2006) 267.
[5]. L.C. Meher, D. Vidya Sagar, S.N. Nnik, Renewable and sustainable Energy Review, 10 (2006) 248.

[6]. B.K. De and Bhattacharyya, Wiley-VCH Verlag GmbH, D-69451 Weinheim,1999 p. 404.

[7]. Siti Zullaikah, Chao-Chin Lai, Shaik Ramjan Vali, Yi-Hsu Ju, Bioresource Technology 96 (2005) 1889.

[8]. Mahbub Morshed, Kaniz Ferdous, Maksudur R. Khan, M.S.I Mazumder, M.A. Islam and Md. T. Uddin, Fuel 90 (2011) 2981.

[9]. Jose M Encinar., Juan F. Gonzalez and Antonio Rodriguez-Reinares, Ind. Eng. Chem. Res. 44 (2005) 5491.

[10]. G.H. Jeffery, J Bassett, J Mendham, and R.C. Denney, Vogel's textbook of quantitative chemical analysis, $5^{\text {th }}$ edition. UK: Longman Scientific and Technical 1991.p. 308.

[11]. Official Methods and Recommended Practices of the American Oil Chemists Society, $5^{\text {th }}$ edition, AOCS Press, Champaign, 1998, pp. 6-38.

[12]. R.M. Joshi and M.J. Pegg, Fuel 86 ( 2007) 143.

\section{NOMENCLATURE}

\begin{tabular}{|l|l|l|}
\hline Symbol & Meaning & Unit \\
\hline $\mathrm{M}$ & Molarity & Mol/L \\
\hline $\mathrm{N}$ & Normality & Equivalent $\mathrm{mol} / \mathrm{L}$ \\
\hline
\end{tabular}

